\title{
A Novel Aza-Nazarov Cyclization of Quinazolinonyl Enones: A Facile Access to $C$ - Ring Substituted Vasicinones and Luotonins
}

\author{
Sivappa Rasapalli, ${ }^{a^{\star}}$ Vamshikrishna Reddy Sammeta, ${ }^{a}$ Zachary F. Murphy, ${ }^{a}$ Yanchang Huang, ${ }^{a}$ \\ Jeffrey A. Boerth ${ }^{a}$, James A. Golen ${ }^{a}$ and Sergey N. Savinov \\ ${ }^{a}$ Department of Chemistry and Biochemistry, University of Massachusetts, 287 Old Westport Rd, N. Dartmouth, MA-02747, \\ USA. \\ ${ }^{b}$ Department of Biochemistry and Molecular Biology. UMass Amherst, Amherst, MA-01003, USA \\ srasapalli@umassd.edu
}

Received Date (will be automatically inserted after manuscript is accepted)

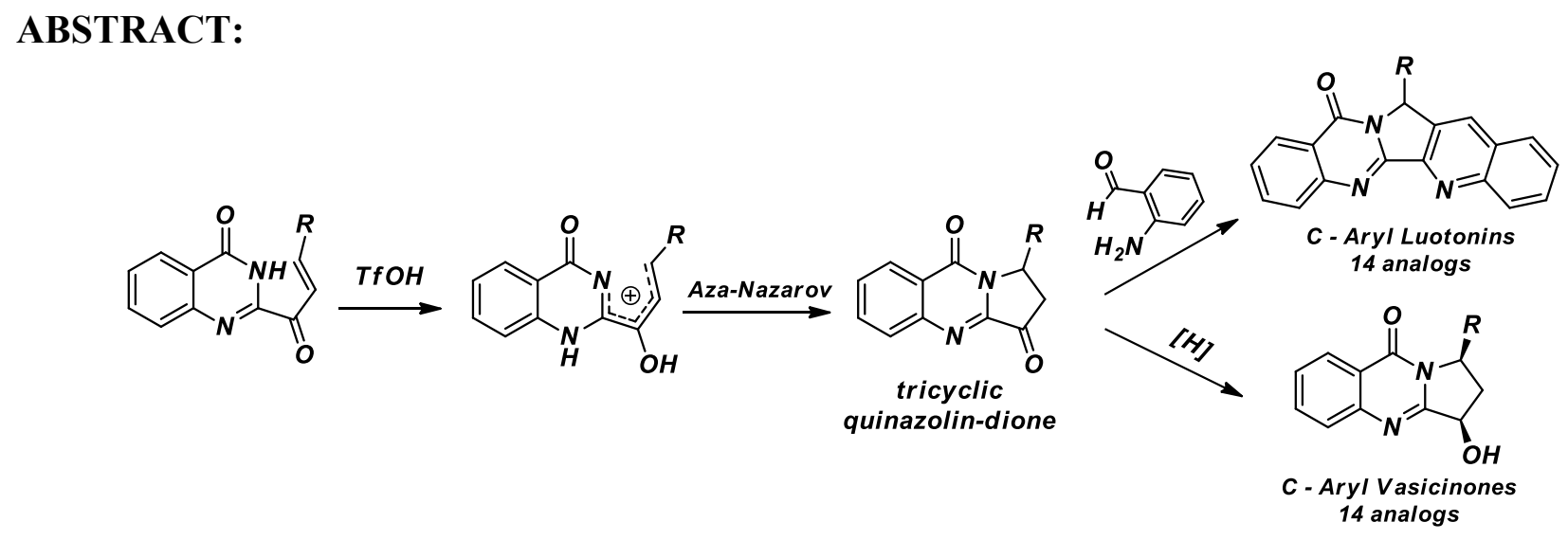

A facile four-step synthetic access to $\boldsymbol{C}$-ring substituted luotonins and vasicinones has been realized via a novel super acid mediated aza-Nazarov cyclization of quinazolinonyl enones. The regioselectivity of the cyclization is highly dependent on proton availability and overall polarity of the reaction medium.

Quinazolinone is one of the most privileged pharmacophores in medicinal chemistry. ${ }^{1,2}$ There are more than 20 drugs that are currently in market containing thequinazolinone core. ${ }^{3}$ Additionally, pharmacologically important natural products harboring the quinazolinone core are also abundant and are known to possess wide range of medicinal properties: including anti-tumor, anti-inflammatory, antihypertensive, anticonvulsant, antifungal and antimicrobial activities and offer attractive scaffolds for drug discovery. ${ }^{4}$ Luotonin A (1a) is one such natural product containing quinazolin4(3H)-one core and was isolated from Peganum nigellastrum, a traditional Chinese medicinal plant, ${ }^{5}$ along with five other congeners, luotonins B-F., ${ }^{6,7}$ Luotonin A exhibited significant cytotoxicity towards murine leukemia P-388 cell line $\left(\mathrm{IC}_{50}=1.8 \mu \mathrm{g} / \mathrm{mL}\right)^{5}$ when compared to other luotonins. Later in 2003, Hecht and coworkers discovered that luotonin A exerts its activity through inhibition of topoisomerase-I (topo-I), through mechanism of action analogous to camptothecin (CPT) (3) ${ }^{8}$ which attracted the attention of medchem and synchem communities alike. ${ }^{9}$ This increased attention is partly due to toxic side effects associated with CPT and its analogs, due to hydrolysis of the $E$-ring in basic pH and higher expected chemical stability of luotonins than that seen with the CPT scaffold (Figure 1). ${ }^{10,11}$ Although the CPT analogs offer better potency in terms of topo-I inhibition than luotonin $\mathrm{A}$ the later ${ }^{12}$ provides an alternate and attractive chemical platform for potential modifications because of its highly stable aromtic $E$-ring. As a result, several reports have appeared on total synthesis and structural modifications of luotonin A in an effort to find a more potent lead. ${ }^{13,14}$ The synthetic modifications reported thus far on the luotonin A core include principally alkyl and haloalkyl substituents on $A$ ring ${ }^{15,16}$; aryl ${ }^{12}$, alkyl ${ }^{15}$, aminoalkyl ${ }^{17}$, and trifluoromethyl 
substituents on $B$-ring ${ }^{18}$; halo, methoxy and methyl substituents on $E$-ring. ${ }^{19}$ In comparison to the other rings, the reports on modifications of $C$-ring have been rather limited (i.e., $\quad C$-ring methoxycarbonyl ${ }^{20}$ and acetylamino $^{21}$ ). It is presumably due to the dearth and difficulty in synthetic routes to access the same, similar to the current situation with CPT. ${ }^{22}$ Another reason for the appartent lack of efforts directed towards the $C$-ring substitutions could, in part, be due to the fact that the CPT analogs with hydroxyl, alkoxy, amino, and acetoxy groups on the $C$-ring showed reduced cytotoxic activity ${ }^{23}$, ${ }^{24}$, as did naturally occurring $C$-ring substituted luotonins B (hydroxyl) and E (methoxy). However, encouraged by the report ${ }^{25}$ that the 5-ethylene CPT analogue does not lose its antitumor activity as the ethylene substituent is assumed to lie in the molecular plane with no extra $\mathrm{H}$ bonding capabaility, we reasoned that installing alkyl or aryl groups on the $C$-ring might prove benficial in overcoming the decreased levels of topo-I inhibition activity displayed by achiral and flat luotonin A. ${ }^{26} \mathrm{We}$ were also intrigued by the opportunity to identify natural product-derived that might offer anti-cancer activity through a novel mecahnsim of actions, independent of topo-I inhibition. ${ }^{27,10}$ Thus, due to our longstanding interest in this family, ${ }^{28}$ we set out to develop a synthetic strategy for facile $C$-ring substituted luotonin A analogues to identify a potential lead for further optimization, and amenable to other CPT family of alkaloids such as 22Hydroxyacuminatine (6), ${ }^{29}$ rosettacin $^{30}$ and quinazolinone alkaloids such as rutaecarpine (4), ${ }^{31}$ and evodiamine. ${ }^{32}$ (Figure 1) Towards that, we have investigated the cyclizations of quinazolinonyl chalcones to access the $C$ ring aromatic substituted luotonins via the intermediacy of tricyclic ketones that in turn, enabled access to yet another family of natural quinazolinones, $C$-ring substituted variants of vasicinones (2) and nigellastrine I (5), Acetylcholinesterase inhibitors extracted from Peganum harmala and Peganum nigellsatrum respectively. ${ }^{33}$ Herein, we report the details of our studies.

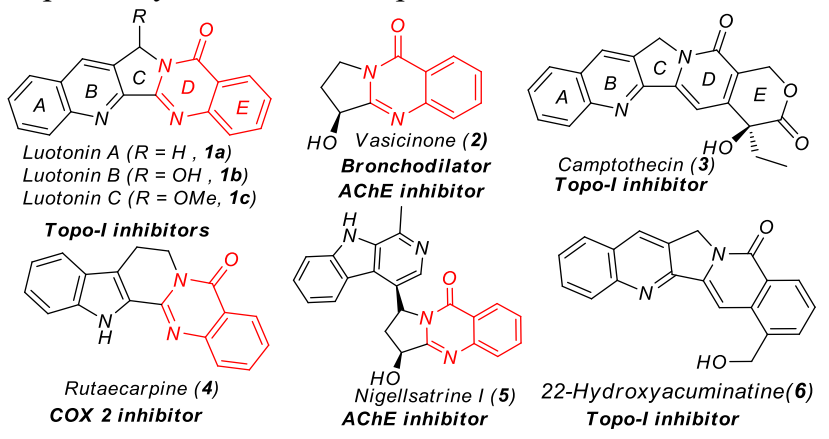

Figure 1. Structures of quinazolinone containing bioactive natural products and camptothecin.

Accordingly, our retrosynthetic plan to access the $C$ ring substituted luotonins and vasicinones is shown in Scheme 1. The AB rings of luotonins are proposed to be assembled through classical Friedlander condensation ${ }^{34}$ of the tricyclic ketone intermediate $\mathbf{8}$ whose carbonyl group was also planned to be used as a handle for accessing vasicinone analogs through hydride reduction. ${ }^{35}$

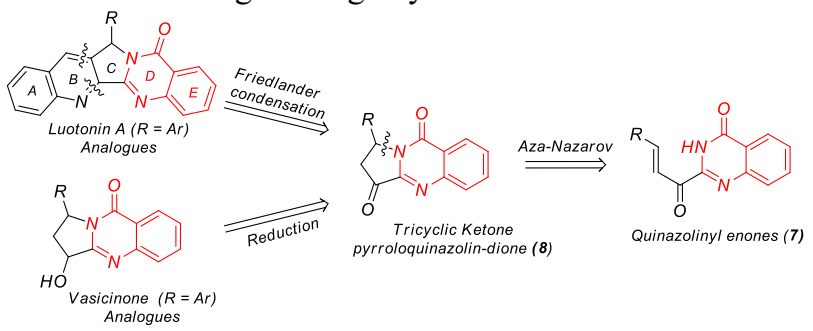

Scheme 1. Retrosynthesis of $C$-ring substituted luotonins

Our efforts commenced with finding the reaction conditions for the key cyclization to form the $C$-ring from the readily available quinazolinonyl enones (7). ${ }^{36,37} \mathrm{We}$ thought the cyclization could possibly be effected through an intramolecular aza-Michael reaction (IMAMR) ${ }^{38}$ Thus several bases of variable strength $\left(\mathrm{K}_{2} \mathrm{CO}_{3}, \mathrm{NaOMe}\right.$, $\mathrm{NaOEt}, \mathrm{NaH}$, LDA) were inititally screened for the cyclization of $7 \mathbf{a}$ at various temperature conditions, including highly elevated temperatures $\left(\sim 200^{\circ} \mathrm{C}\right)$, range of solvents. However, these attempts of promoting cyclization under basic condition met with no success. Next, we envisioned that instead of activating the nucleophile by converting the quinazolinonyl nitrogen to an anion to cyclize at the $\beta$-carbon of the enone, we could rather activate the enone electrophile by utilizing an acid promoter. Our initial attempts using Lewis acids, such as metal triflates (zinc, scandium, iron and indium), in DCE $\left(80^{\circ} \mathrm{C}\right)$ did not meet with success to provide the desired tricyclic product, even upon refluxing for $16 \mathrm{~h}$. Also, the acids such as conc. $\mathrm{HCl}, \mathrm{H}_{2} \mathrm{SO}_{4}$ and TFA were to no avail, prompting us to probe super acids for the activation. Thus, we turned to triflic acid (TfOH), and proceeded with finding a suitable solvent system for employing superacid activation, which proved to be nontrivial. From our previous unsuccessful efforts involving regular acid catalysts, we envisioned that using one of them as a solvent (e.g., TFA) along with TfOH would be more effective for the activation of enone compared to neat conditions. Thus, we have tried varying amounts of TfOH: substoichiometric amounts $(0.25 \&$ 0.5 equiv.at $65^{\circ} \mathrm{C}$ for $2 \mathrm{~h}$ ) led to a relatively polar product (per TLC) as a major product, whereas a reaction with lequiv.TfOH $\left(65^{\circ} \mathrm{C}, 2 \mathrm{~h}\right)$ produced two products the same polar material as above and a less polar product, with a considerable amount of starting material left as unreacted in each case, indicating the need for increased amounts of super acid to bring the reaction to completion. After screening reaction conditions further, we were able to achieve complete conversion of starting material to the less polar product in 10 minutes with 4equiv. TfOH in TFA at RT. However, we were unable to isolate the product through conventional aqueous base workup, as it was degrading to a complex mixture (observed through TLC). In our further workup efforts, we noticed that slow addition of water to the pre-cooled reaction mixture 

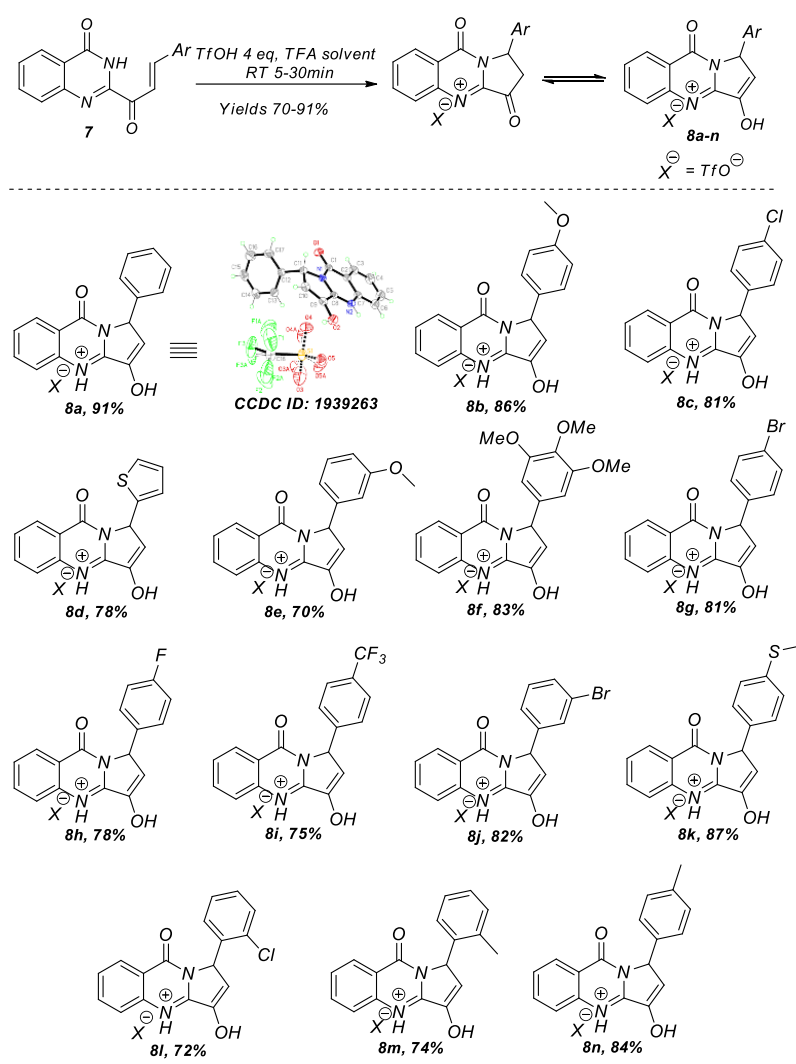

Scheme 2. TfOH promoted cyclization of quinazolinonyl enones

precipitated desired tricyclic product 8a (as judged by Xray crystallography) as a triflate salt of the enol tautomer in $91 \%$ yield (salt basis). We then successfully applied this reaction and workup conditions to the rest of the enone series to obtain tricyclic enols $\mathbf{8 b}-\mathbf{n}$ as their triflate salts (Scheme 2). We observed that enones with electronrich aryls (e.g., 7b, 7e \& 7f) afforded the product in under 10 minutes., whereas those with electron-deficient aryls (e.g., $7 \mathbf{g}, \mathbf{7 h}, \mathbf{7 j} \& \mathbf{7 l}$ ) required at least 15 minutes for the reaction completion, with $7 \mathbf{i} \quad\left(p-\mathrm{CF}_{3} \mathrm{C}_{6} \mathrm{H}_{4}-\right)$ being consumed only after 30 minutes.

In our further studies we probed into the mechanistic characteristics of the key cyclization step described in Scheme 2. We initially investigated the role of TfOH/TFA system by exchanging TFA with a less acidic solvent, acetic acid. The reaction of compound $7 \mathbf{a}$ in $\mathrm{TfOH}(4 \mathrm{eq}$.) $/ \mathrm{AcOH}$ revealed the formation of the polar material, but no desired product was observed, and the starting material was not completely consumed even after $2 \mathrm{~h}$ of heating at $60^{\circ} \mathrm{C}$. The above outcome suggested that the strongly acidic conditions are indeed required for the exclusive formation of the less polar desired product, whereas less acidic conditions lead to the formation of the more polar byproduct. With this observation, we decided to isolate and characterize the polar byproduct. We optimized reaction conditions to a less acidic environment and successfully obtained this material as an exclusive product in an acceptable yield (up to $56 \%$ yield on the salt basis). The X-ray crystallographic studies revealed that the more polar unstable product is a regioisomer $\left(\mathbf{8 a}^{\mathbf{\prime}}\right)$ of compound 8a (Scheme 3) i.e., an angularly fused tricyclic

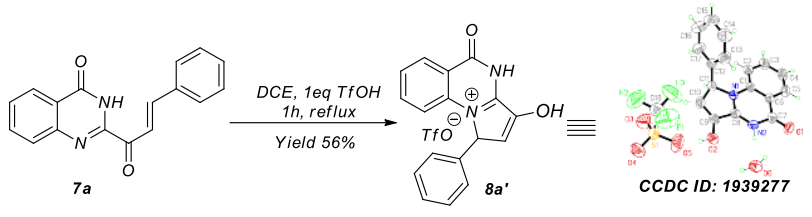

Scheme 3. Synthesis of angularly fused tricycle 8a'

enol. ${ }^{39}$ While the acidity of the reaction media was proven essential for promoting these cyclizations, the mechanistic rationale for the regiochemical outcomes under these conditions i.e., linearly fused tricycle $\mathbf{8 a}$ (4equiv.TfOH/TFA) or angularly fused regioisomer $\mathbf{8 a}$ ' ( $\leq$ 1 equiv.TfOH/DCE) remained to be uncovered. The two conditions vary not only in concentration of superacid, but also in polarity of media, which also contributes to distinct proton availability and must somehow account for the observed regioselectivities. Mechanistically, this novel cyclization could be explained through one of the two plausible pathways, anti-Baldwin IMAMR (5-endo-trig) or thermally allowed pericyclic aza-Nazarov cyclization, ${ }^{40}$ both potentially benefiting from a general acid promotion. Previous studies conducted by Klumpp ${ }^{41}$ et al. on aza-Nazarov cyclizations of $\mathrm{N}$-acyliminium salts under superacid catalysis suggested that the cyclization proceeds through dicationic species, as initially proposed by $\mathrm{Olah}^{42}$ et al. and $\mathrm{Shudo}^{43}$ et al. for reactions with $\mathrm{TfOH}$ under the conditions of superelectrophilic solvation. On the other hand, Dieker ${ }^{44}$ et al. disclosed an aza-Nazarov cyclization of 1-azapenta-1,4-dien-3-ones via a monoprtonated reactive intermediate. Although it is appealing to assign the regioselectivity of the chalcone cyclization under the more or less acidic conditions to the extent of protonation (i.e., a possible double vs single protonation of the cyclization precursor), other mechanistic possibilities could not be excluded without a detailed computational analysis of the reactive system.

To rationalize the observed regioselectivities, the cyclization reaction was analyzed via a quantum mechanical (QM) approach using program Jaguar (Schrödinger, LLC). This analysis is complicated by a well recognized lactam-lactim tautomeric equilibrium of quinazolinones, ${ }^{45}$ with $4-(3 H)$-quinazolinone being the dominant tautomer, followed by $4-(1 H)$-quinazolinone, and 4-hydroxyquinazoline, the latter being the least stable tautomer (Figure S1). Multiple proton-accepting centers on each tautomer predict, in turn, a rather complex distribution of monoprotonated species upon superacid treatment. QM-based $\mathrm{p} K_{\mathrm{a}}$ calculations also confirm relatively poor overall basicity of quinazolinone chalcone system, necesitating the use of super acid to promote protonation, critical for the cyclization reaction (Figure S1). Thus, the most basic site in the dominant $3 H$ lactam tautomer, chalcone carbonyl, is predicted to have aqueous $\mathrm{p} K_{\mathrm{a}}$ in the -0.9 to -0.2 range (depending on the enone conformational state), whereas in the less stable $1 H$ lactam tautomer the most basic site becomes the ring nitrogen $\left(\mathrm{p} K_{\mathrm{a}}\right.$ 0.4-0.6). The least contributing 4hydroxyquinazoline tautomer also favors protonation at 
the carbonyl $\left(\mathrm{p} K_{\mathrm{a}}\right.$ 1.1-3.9). This inverse relationship between tautomer stability and basicity helps understand the distribution in the resulting monoprotonated species, with lactim-derived variants dominating (Table S1). The site of protonation becomes important in the next step, since only species entering into exothermic (lactams) or mildly endothermic (lactims) cyclizations were those with protonations at the chalcone carbonyls and proton-free quinazolinone nitrogens (Table S1). Both linear and angular lactim tricycles can subsequently tautomerize to the more stable lactams, completing a likely pathway of this reaction, with the linear tricyclic lactam being a more stable of the two regioisomeric products $(-2.4$ vs $1.2 \mathrm{kcal} / \mathrm{mol}$ ). Notably, all diprotonated precursors proved too unstable to cyclize exothermically, due to, presumably, higher charge-charge repulsion in the more compact tricyclic systems, suggesting that monoprotonation must account for the observed regioselectivities for the reactions in both proton-rich and proton-deficient media.

Search for transition states for each carbonylonium reactant provided evidence that kinetic and thermodynamic controls could account for the selective production of angular and linear tricycles, respectively. Thus, formation of the angular system proceeds via a lower energy transition state than that of the linear one (Scheme S1). Both transition states (TSs), validated via vibrational frequencies display planarity of the quinazolinyl fragment and significant disruption of the $\pi$-conjugation in the enone fragment, with $\mathrm{C}-\mathrm{C}=\mathrm{C}-\mathrm{C}$ dihedral angle ranging from $138.3^{\circ}$ to $140.4^{\circ}$ in the TSs leading to linearly and angularly fused systems, respectively (Figure S2). The Frontier Molecular Orbitals for both transition states involve the $\pi$-systems exclusively of both quinazolinone and chalcone, confirming the aza-Nazarov nature of the cyclization process. The selectivity of each process could also be enhanced by the reaction media, which could either facilitate tautomerization required for reversibility of the cyclization step (4 equiv.TfOH/TFA) or, apparently, inhibit it $(\leq 1$ equiv.TfOH/DCE).

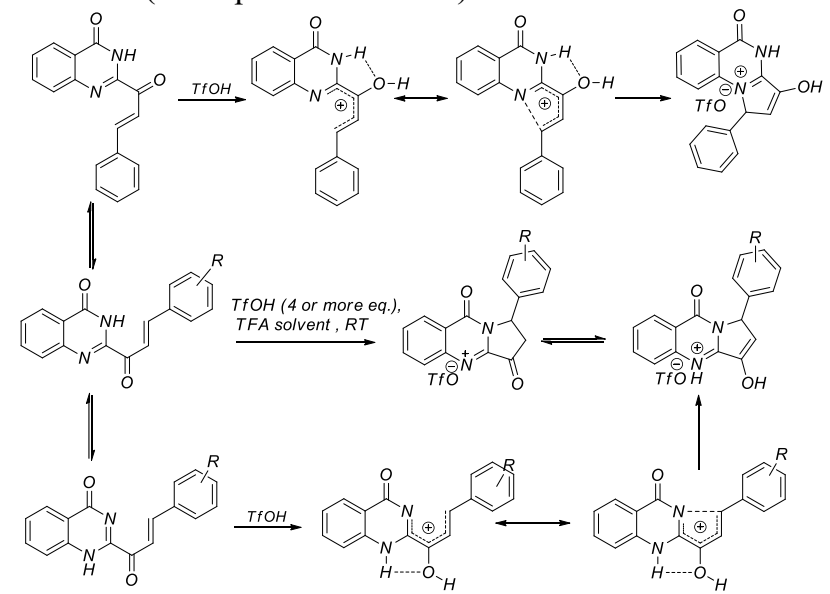

Scheme 4. Proposed mechanism for the formation of tricyclic enols (8a-n) and regioisomer 8a'
Having obtained reasonable quantities of tricyclic ketone equivalents in a protonated enol form in an expeditious way in three steps from anthranilamide, we investigated the conditions to utilize these synthetic intermediates to access vasicinone and luotonin analogs. Thus, the compounds 8a-n as obtained without any further purification were subjected to reduction with $\mathrm{NaBH}_{4}$ in methanol at $0^{\circ} \mathrm{C}$-RT to afford vasicinone analogs 9a-n as single cis diasteriomers (Scheme 5).
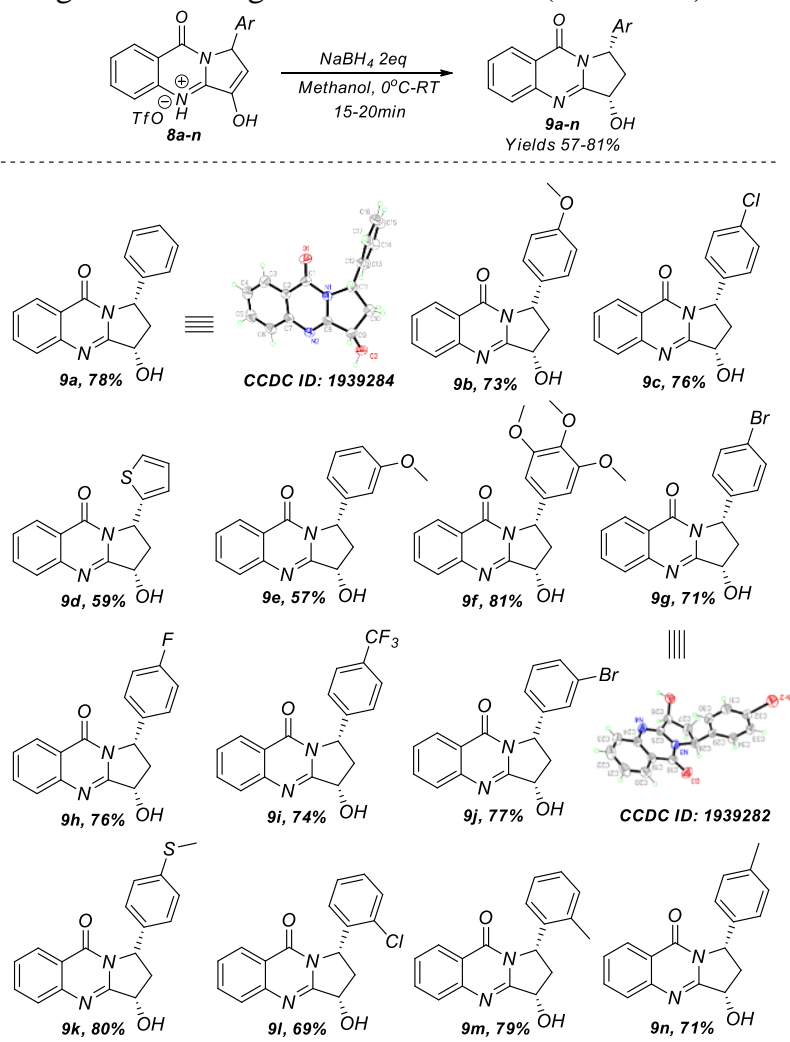

Scheme 5. Synthesis of vasicinone analogs (9a-n)

We thought it would be sufficient to treat the tricyclic ketones with 2-amino benzaldehyde as they were isolated as triflates of enolic tautomers and induce selfpromoted Friedlander condensation to annulate the $\mathrm{AB}$ ring (quinoline) core on to the $\mathrm{CDE}$ cores. Thus, mere refluxing of compounds 8a-n with 2-aminobenzaldehyde in ethanol cleanly afforded luotonin analogs 10a-n (Scheme 6) in good yields.

In conclusion, we have uncovered a novel azaNazarov cyclization of quinazolinyl enones to tricyclic enols. TfOH/TFA system was found to be effective for this key aza-Nazarov cyclization step, and the regioselectivity of it is dependent upon proton availability in the reaction medium. We have successfully showcased the utility of the same and developed a facile four-step synthesis of library of $C$-ring aryl substituted luotonins and vasicinones from readily available anthranilamide. The synthesized library of vasicinones (9a-n) and luotonins (10a-n) are being evaluated for both general cytotioxicity and topo-I inhibition, and results will be reported elsewhere in due course along with their mechanism of 

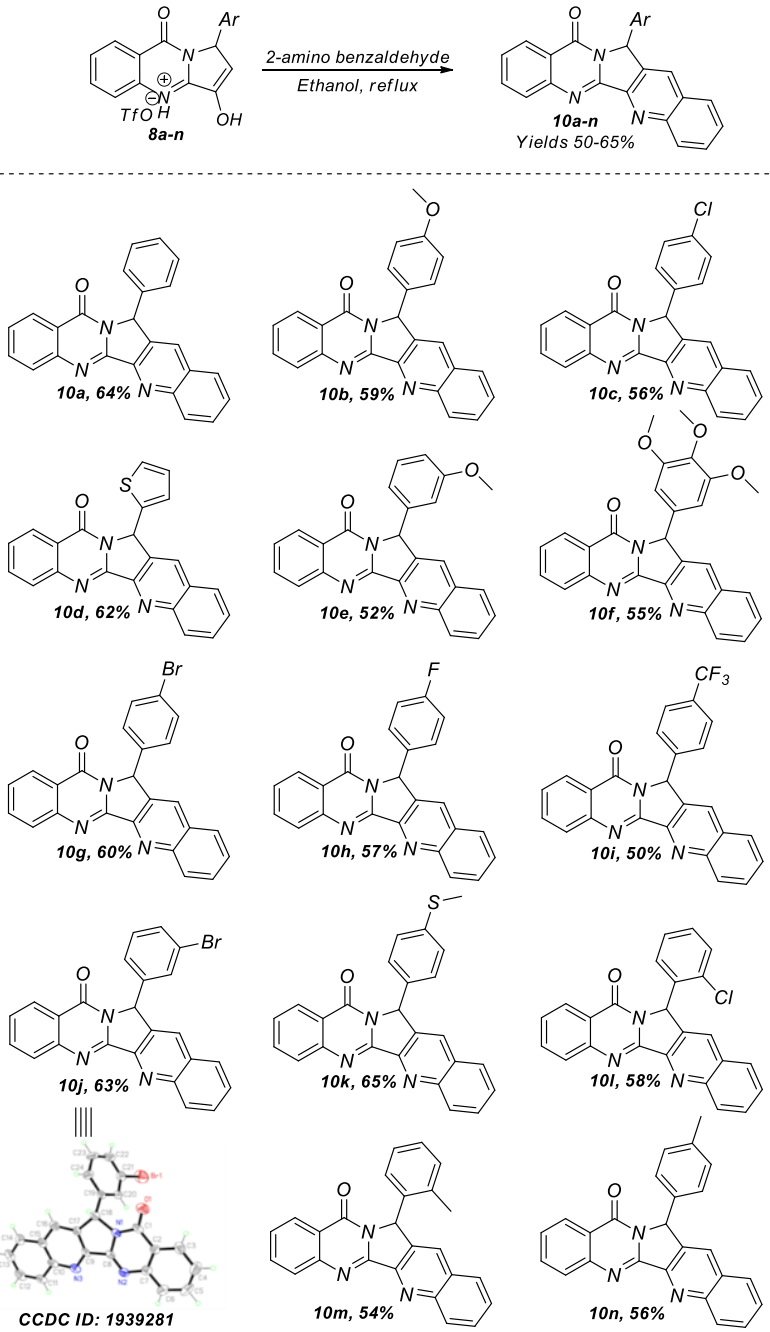

(2) Jafari, E.; Khajouei, M. R.; Hassanzadeh, F.; Hakimelahi, G. H.; Khodarahmi, G. A. Res. Pharm. Sci. 2016, 11, 1.

(3) Tiwary, B. K.; Pradhan, K.; Nanda, A. K.; Chakraborty, R. J. Chem. Bio. \& Ther. 2015, 1, 104.

(4) He, D.; Wang, M.; Zhao, S.; Shu, Y.; Zeng, H.; Xiao, C.; Lu, C.; Liu, Y. Fitoterapia 2017, 119, 136.

(5) Ma, Z.-Z.; Hano, Y.; Nomura, T.; Chen, Y.-J. Heterocycles 1997, 46, 541.

(6) Ma, Z.-Z.; Hano, Y.; Nomura, T.; Chen, Y.-J. Phytochemistry 2000, 53, 1075.

(7) Ma, Z.-Z.; Hano, Y.; Nomura, T.; Chen, Y.-J. Heterocycles 1999, 51, 1883.

(8) Cagir, A.; Jones, S. H.; Gao, R.; Eisenhauer, B. M.; Hecht, S. M. J. Am. Chem. Soc. 2003, 125, 13628.

(9) Liang, J. L.; Cha, H. C.; Jahng, Y. Molecules 2011, 16, 4861

(10) Li, F.; Jiang, T.; Li, Q.; Ling, X. Am. J. Cancer. Res. 2017, 7, 2350.

(11) Wallace, B. D.; Wang, H.; Lane, K. T.; Scott, J. E.; Orans, J.; Koo, J. S.; Venkatesh, M.; Jobin, C.; Yeh, L. A.; Mani, S.; Redinbo, M. R. Science 2010, 330, 831.

(12) González-Ruiz, V.; Pascua, I.; Fernández-Marcelo, T.; Ribelles, P.; Bianchini, G.; Sridharan, V.; Iniesta, P.; Ramos, M. T.; Olives, A. I.; Martín, M. A.; Menéndez, J. C. PLoS One 2014, 9, e95998.

(13) For reviews on total synthesis of luotonin A, see: (a) Liang, J. L.; Cha, H. C.; Jahng, Y. Molecules 2011, 16, 4861. (b) Huang, W. P.; Liu, J. L.; Wang, C. L. Chin. J. Org. Chem. 2009, 29, 1533.

(14) For recent reports on the total synthesis of luotonin A, see: (a) Almansour, A. I.; Kumar, R. S.; Arumugam, N.; Bianchini, G.; Menéndez, J. C.; Al-thamili, D. M.; Periyasami, G.; Altaf, M. Tetrahedron Lett. 2019, 60 1514. (b) Ibric, A.; Eckerstorfer, S.; Eder, M.; Louko, I.; Tunjic, L.; Heffeter, P.; Schueffl, H. H.; Marian, B.; Haider, N. Molecules 2019, 24, 716. (c) Baguia, H.; Deldaele, C.; Romero, E.; Michelet, B.; Evano, G. Synthesis 2018, 50, 3022. (d) Atia, M.; Bogdán, D, Brügger, M.; Haider, N.; Mátyus, P. Tetrahedron 2017, 73, 3231. (e) Kwon, S. H.; Seo, H. A.; Cheon, C. H. Org Lett. 2016, 18, 5280. (f) Haider, N.; Meng, G.; Roger, S.; Wank, S. Tetrahedron 2013, 69, 7066. (g) Nagarapu, L.; Gaikwad, H. K.; Bantu, R. Synlett 2012, 23, 1775. (h) Natsuki, K.; Shindo, T.; Toyota, M. Heterocycles 2012, 84, 1301. (i) Potewar, T. M.; Kathiravan, M. K.; Chothe, A. S.; Srinivasan, K. V. Eur. J. Chem. 2011, 2, 235.

(15) Tangirala, R.; Antony, S.; Agama, K.; Pommier, Y.; Curran, D. P. Synlett 2005, 18, 2843.

(16) Tseng, M. C.; Chu, Y. W.; Tsai, H. P.; Lin, C. M.; Hwang, J.; Chu, Y. H. Org Lett. 2011, 13, 920.

(17) Mason, J. J.; Bergman, J. Org. Biomol. Chem. 2007, $5,2486$.

(18) Golubev, A. S.; Bogomolov, V. O.; Shidlovskii, A. F.; Dezhenkova, L. G.; Peregudov, A. S.; Shtil, A. A.; Chkanikova, N. D. Russ. Chem. Bull. 2010, 59, 209.

(19) Cagir, A.; Eisenhauer, B. M.; Gao, R.; Thomas, S. J.; Hecht, S. M. Bioorg. Med. Chem. 2004, 12, 6287.

(20) Gavara, L.; Boisse, T.; H'enichart, J.-P.; Da"ıch, A.; Rigo, B.; Gautret, P. Tetrahedron 2010, 66, 7544.

(21) Ma, Z.; Hano, Y.; Nomura, T.; Chen, Y. Bioorg. Med. Chem. Lett. 2004, 14, 1193.

(22) a) Verma, R. P.; Hansch, C. Chem. Rev. 2009, 109, 213. b).Amin, S.A, Nilanjan, A.; Jha, T.; Gayen, S.; AntiCancer Agents. Med.Chem. 2018, 18, 1796

(23) Thomas, C. J.; Rahier, N. J.; Hecht, S. M. Bioorg Med. Chem. 2004, 12, 1585.

1. Gatadi, S.; Lakshmi, T. V.; Nanduri, S. Eur. J. Med. Chem. 2019, 170, 157. 
(24) (a) Subrahmanyam, D.; Sarma, V. M.; Venkateswarlu, A.; Sastry, T. V. R. S.; Kulakarni, A. P.; Srinivasa Rao, D.; Krishna Reddy, K. V. S. R. Bioorg. Med. Chem. 1999, 7, 2013. (b) Samori, C.; Guerrini, A.; Varchi, G.; Fontana, G.; Bombardelli, E.; Tinelli, S.; Beretta, G. L.; Basili, S.; Moro, S.; Zunino, F.; Battaglia, A. J. Med. Chem. 2009, 52, 1029.

(25) Sugimori, M.; Ejima, A.; Ohsuki, S.; Matsumoto, K.; Kawato, Y.;Yasuoka, M.; Tagawa, H.; Terasawa, H. Antitumor agents. VI. Heterocycles, 1994, 38, 81.

(26) There are no $C$-ring alkyl or aryl substitutions reported on Luotonin A; For semi synthesis of 5substituted CPTs, see: (a) Meruva, S. B.; Raghunath, A.; Anil Kumar, N.; Vasudev, R.; Syam Kumar, U. K.; Dubey. P. K. J. Heterocycl. Chem. 2011, 48, 540. (b) Li, D. Z.; Pan, X. D.; Liu, H. Y.; Wu, S. Chin. Chem. Lett. 2008, 19, 1202.

(27) Cinelli, M. A. Med. Res. Rev., 2019, 39, 1294.

(28) (a) Chavan, S. P.; Rasapalli, S. Tetrahedron Lett. 2004, 45, 9931. (b) Chavan, S. P.; Rasapalli, S. Tetrahedron Lett. 2004, 45, 3113. (c) Chavan, S. P.; Sivappa, R. Tetrahedron Lett. 2004, 45, 3941. (d) Chavan, S. P.; Sivappa, R. Tetrahedron Lett. 2004, 45, 997.

(29) Xiao, X.; Antony, S.; Pommier, Y.; Cushman, M. J. Med. Chem. 2006, 49, 1408.

(30) Cheng, K.; Rahier, N. J.; Eisenhauer, B. M.; Gao, R.; Thomas, S. J.; Hecht, S. M. J. Am. Chem. Soc. 2005, 127, 838.

(31) Moon, T. C.; Murakami, M.; Kudo, I.; Son, K. H.; Kim, H. P.; Kang, S. S.; Chang, H. W. Inflammation Res. 1999, 48,621 .

(32) Kobayashi, Y.; Nakano, Y.; Kizaki, M.; Hoshikuma, K, Yokoo, Y.; Kamiya, T. Planta Med. 2001, 67, 628.

(33) (a) Zheng, X. Y.; Zhang, Z. J.; Chou, G. X.; Wu, T.; Cheng, X. M.; Wang, C. H.; Wang, Z. T. Arch Pharm Res. 2009, 32, 1245. (b) Joshi, B. S.; Bai, Y.; Puar, M. S.; Dubose, K. K.; Pelletier, S. W. J. Nat. Prod. 1994, 57, 953. (34) MarcoContelles, J.; Perez-Mayoral, E.; Samadi, A.; Carreiras, M. C.; Soriano,'E. Chem. Rev. 2009, 109, 2652.

(35) Rasapalli, S.; Huang, Y.; Sammeta, V. K. R.; Anthony Y. N.; Chavan, S. P. under process of submission, 2019.

(36) Cao, S. L.; Xu, X.; Liao, J.; Han, X.; Yuan, X. L.; Wang, F.; Hu, X. Preparation of chalcone analogs containing 4-oxoquinazolin-2-yl and their application as anticancer agents. Faming Zhuanli Shenqing. CN 105503745, 2016

(37) Rasapalli, S.; Sammeta, V. K. R.; Murphy, Z. F.; Melander, R. J.; Melander, C. under process of submission, 2019.

(38) Sanchez-Rosello, M.; Acena, J. L.; Simon-Fuentes, A.; del Pozo, C. Chem. Soc. Rev. 2014, 43, 7430.

(39) Our efforts to isolate these angular enols have not been successful thus far as they seem to be labile upon exposure to atmosphere; we would be undertaking the one pot derivitization of the same in our future efforts.

(40) (a) Di Grandi, M. J. Org. Biomol. Chem. 2014, 12, 5331. (b) Vinogradov, M. G.; Turova, O. V.; Zlotin, S. G. Org. Biomol. Chem. 2017, 15, 8245.

(41) Klumpp, D. A.; Zhang, Y.; O'Connor, M. J.; Esteves, P. M.; de Almeida, L. S. Org. Lett. 2007, 9, 3085.

(42) Olah, G. A.; Klumpp, D. A. Acc. Chem. Res. 2004, 37, 211.

(43) Saito, S.; Sato, Y.; Ohwada, T.; Shudo, K. J. Am. Chem. Soc. 1994, 116, 2312.

(44) Dieker, J.; Fröhlich, R.; Würthwein, E.-U. Eur. J. Org. Chem. 2006, 23, 5339.
(45) We'ber, C.; Demeter, A.; Szendrei, G. I.; Greiner, I. Tetrahedron Lett. 2003, 44, 7533.

(46) Kerr, D. J.; Miletic, M.; Manchala, N.; White, J. M.; Flynn, B. L. Org. Lett. 2013, 15, 4118.

(47) Grenet, E.; Martinez, J.; Salom-Roig, X. J. Asian J. Org. Chem., 2017, 6, 189. 